\title{
Dinâmicas de expansão do arranjo urbano-regional Brasília-Anápolis-Goiânia*
}

\author{
Expansion dynamics of the Brasília-Anápolis-Goiania \\ urban-regional arrangement
}

Marcos Bittar Haddad

Rosa Moura

\section{Resumo}

Arranjos urbano-regionais constituem categoria socioespacial que articula aglomerações e centros em uma mesma unidade. Configuram-se sob célere qualificação/desqualificação de espaços pela redefinição de funções, criando territórios extensos, permeados por vazios. São representativos do estágio contemporâneo da metropolização, que passa a engendrar novas morfologias urbanas, articuladas e densas, ao mesmo tempo descontínuas, que sustentam a ampliação geográfica do processo de acumulação. Tomando como objeto o arranjo Brasília-Anápolis-Goiânia, discutem-se, neste artigo, suas atuais dinâmicas de expansão, a ação do setor imobiliário, sob forte influência da renda gerada pelo agronegócio, e as implicações regionais. Com particularidade no modelo de expansão de Goiânia e Anápolis, busca-se mostrar que a riqueza gerada no entorno induz a valorização urbana, contudo não rompe a desigualdade existente, que se acentua ao serem criados espaços cada vez mais fragmentados.

Palavras-chave: arranjo urbano-regional; expansão urbana; mercado imobiliário; Brasília; Anápolis; Goiânia.

\begin{abstract}
Urban-regional arrangements are a socio-spatial category that articulates agglomerations and centers in one unit. They are configured under a fast qualification/disqualification of spaces through redefinition of functions, and create extensive territories permeated by urban voids. This category is representative of the contemporary stage of metropolization, which has started engendering new urban morphologies that are articulated and dense, but discontinued, and support the geographical enlargement of the accumulation process. Having as object the Brasilia-Anápolis-Goiânia arrangement, we discuss, in this article, its current expansion dynamics, the action of the real estate industry, under the strong influence of income generated by agribusiness, and regional implications. Specifically in the expansion model of Goiânia and Anápolis, we attempt to show that the wealth generated in the surroundings induces urban valuation without reducing the existing inequality, which is intensified when increasingly fragmented spaces are created.
\end{abstract}

Keywords: urban-regional arrangement; urban expansion; real estate market; Brasília; Anápolis; Goiânia. 


\section{Introdução}

0 arranjo urbano-regional ${ }^{1}$ formado por Brasília, Anápolis e Goiânia caracteriza-se pela conectividade e forte dinâmica entre esses núcleos urbanos. Fruto de uma intensa exploração capitalista, sobretudo imobiliária, a realidade existente nessas cidades tem se transformado cotidianamente. Em sua composição destacam-se duas cidades construídas para serem capitais: Brasília, capital federal, e Goiânia, capital de Goiás. Anápolis, cidade mais antiga, serviu de apoio durante o processo de construção dessas outras duas. 0 fato de se tratar de cidades planejadas, construídas por intervenção do poder público, sugere que tais construções também tiveram o intuito de favorecer a valorização do capital imobiliário.

As políticas de desenvolvimento nacional, desde a Marcha para o Oeste, tentavam fazer dessa região uma grande produtora de alimentos. Após a construção de Brasília, a região integrou-se ao restante do País por uma malha rodoviária, o que favoreceu as migrações. 0 caráter econômico, que a princípio sempre se quis dar à região, consolidou-se, a partir dos anos 1990, com o agronegócio, que contribuiu com o crescimento do mercado imobiliário, principalmente nas cidades e em seus arredores, caso de Goiânia e de Brasília. Com o tempo, essas cidades foram absorvendo parte da renda originada pela dinâmica econômica que se consolidava na Região Centro-Oeste, oriunda da intensificação do agronegócio, baseado numa produção de commodities altamente tecnificada, majoritariamente voltada para o mercado externo e geradora de alta renda, particularmente aos empresários da agricultura e pecuária.
0 arranjo espacial em análise compreende mais que essas cidades polos, englobando os municípios de suas regiões de articulação imediata (IBGE, 2013). Conforma uma área extensa, permeada por fluxos e conexões multidirecionais que evidenciam forte grau de articulação entre si, em um complexo universo de relações econômicas, sociais e institucionais.

Esse padrão de configuração espacial, morfologicamente descontínuo e expandido, peculiariza o atual estágio de metropolização no Brasil e constitui a localização mais propícia para a acumulação do capital, fundamentalmente o ligado à produção imobiliária. Cabe anotar que, sem a intervenção de políticas públicas, o espaço objeto desse estudo jamais existiria. Em outras palavras, a realidade presente e em constante alteração no planalto central brasileiro deve-se diretamente à intervenção estatal, em parceria com o capital privado.

Tendo como objetivo demonstrar a formação e a composição desse arranjo espacial, o presente artigo estrutura-se em três partes. Na primeira, apresentam-se o arranjo em si, o surgimento de cada cidade e seu gradual crescimento. Na segunda busca-se explicar que a dinâmica imobiliária presente nessas cidades, em especial em Goiânia e Anápolis, em muito se parecendo com o que ocorre nas demais cidades médias ou grandes do País, é fortemente influenciada pela renda gerada pelo agronegócio brasileiro, que no momento é uma das mais importantes atividades econômicas do País. $\mathrm{Na}$ terceira parte, usando de várias referências especificas, discute-se como a dinâmica apresentada expressa a configuração contemporânea da metropolização, que se sintetiza em morfologias urbanas expandidas. 


\section{Apresentação do arranjo}

O surgimento das cidades de Anápolis, Goiânia e Brasília, embora relativamente próximas, deu-se sob circunstâncias diferenciadas no espaço e no tempo. Criadas em diferentes épocas, beneficiaram-se de políticas públicas voltadas para grandes projetos que possibilitaram a instalação de uma infraestrutura que alavancou seu crescimento.

Anápolis tem sua história marcada por ter sido ponto de apoio à construção de duas capitais: Goiânia, de 1933 a 1942, para ser a nova capital de Goiás; e Brasília, de 1955 a 1960, a nova capital federal. Como ponto final da estrada de ferro Mogiana, posição que ocupou por muitos anos, por Anápolis chegavam pessoas, mercadorias e quase todo o material utilizado para a construção dessas novas cidades. Há que se observar que Anápolis era a maior cidade do estado de Goiás e por ser ponto final da estrada de ferro funcionava como um polo comercial que abastecia todo o centro norte de Goiás.

Em 1976, recebeu a instalação do Distrito Agroindustrial de Anápolis (Daia), primeiro distrito industrial de Goiás, com objetivo de abrigar as indústrias que forneceriam suprimentos para Brasília, atendendo, assim, à demanda do grande surto migratório pelo qual passava a região.

Por sua privilegiada posição geográfica, Anápolis tem firmado sua condição de importante ponto logístico, onde se fixam grandes empresas nacionais e internacionais que encontram facilidades para distribuir seus produtos. Está em fase de implantação, na cidade, a Plataforma Logística Multimodal, que reunirá as modalidades de transporte rodoviário, ferroviário e aéreo, fruto de parceria entre 0 governo federal e estadual, sendo a única experiência desse modelo no País, o que reforçará a cidade em sua condição de centro logístico de distribuição.

Goiânia foi fundada em 1933, para ser a nova capital de Goiás, e é considerada a primeira ação do programa Marcha para o Oeste, do Governo Vargas, que tinha por objetivo ocupar a vasta extensão de terras desabitadas no interior do País. Inicialmente planejada para abrigar 50 mil habitantes, até a década de 1970 era considerada uma cidade de médio porte. Sua população não apresentava tendências de crescimento relevante, mas, após o surgimento de Brasília e o desenvolvimento do agronegócio no Centro-Oeste, a imigração para Goiânia intensificou-se e ela tornou-se polo de convergência de fluxos populacionais, superando, em 2010, 1,2 milhões de habitantes. Nesse processo, passou a configurar uma aglomeração metropolitana e, com os municípios de sua vizinhança, passou a experimentar grande crescimento populacional.

Brasília tem origem na concretização de proposta do Governo de levar a capital federal para o interior do Brasil. Essa intenção era manifestada desde 1750, ainda no Império, e se incluiu na Constituição de 1891; mas somente foi executada por Juscelino Kubitschek nos anos 1950. Construída em um local praticamente isolado, a nova capital brasileira, inaugurada em 1960, foi projetada para abrigar 700 mil habitantes em seu Plano Piloto. A população excedente seria destinada a cidades satélites dentro do próprio Distrito Federal. Aos poucos, incentivada pela propaganda governamental, foi ganhando população, fundamentalmente migrantes em busca do sonho da "terra 
prometida". Nos primeiros dez anos, a população ultrapassou os 500 mil habitantes. Parte dessa grande massa não encontrou espaço nas terras esperadas e teve que migrar para regiões próximas. Esse fato foi provocando, aos poucos, uma ocupação não planejada ao redor da nova capital federal $^{2}$ o que impulsionou a expansão demográfica de Anápolis e Goiânia, que apresentavam melhores estruturas e se localizavam com relativa proximidade. As três cidades cresceram juntas a partir da fundação de Brasília, sob uma dinâmica de crescimento entre as mais elevadas do País, trazendo com ela a crescente inserção de municípios periféricos.

Das três cidades, Brasília já nasceu maior que Goiânia, com quase 30 anos de existência, e com muita expressividade no cenário nacional. Em 40 anos, a população de Brasília se quadruplicou (Quadro 1). Goiânia, relativamente, cresceu menos, mas também quadriplicou sua população nesses anos. Anápolis manteve crescimento menor que as capitais. Mesmo assim, de 1970 a 2010, a população anapolina triplicou.

Essas cidades não cresceram sozinhas. Em seus entornos foram surgindo centros urbanos onde população e atividades econômicas complementares se alocaram. Se a sede dos governos federal ou estadual se estabeleceu respectivamente em Brasília e em Goiânia, nas cidades vizinhas se instalaram serviços, motivados, muitas vezes, por maiores incentivos governamentais, como obrigações fiscais reduzidas e população residente. Para esta, mesmo exercendo atividade econômica na capital, como trabalho e estudo, era preferível pagar menos pela moradia, fazendo crescer a população dessas cidades periféricas. Anápolis, não sendo sede de governo, abrigou uma indústria que também fez, crescer dentro de seu território ou em seu entorno, atividades terciárias e população.

Proporcionalmente, a Região Integrada de Desenvolvimento do DF (Ride) cresce mais que a capital (Quadro 2). Brasília, de 1970 a 2010, teve aumento em sua população na ordem de $359,44 \%$, enquanto toda a Ride aumentou em 369,05\%. Já, em Goiânia, esse aumento foi de $229,99 \%$ e $312,71 \%$, respectivamente para a cidade e sua Região Metropolitana (RM). Dos três aglomerados, Anápolis foi o único que cresceu mais que seu entorno, na ordem de $208,77 \%$, enquanto sua microrregião sequer dobrou de tamanho, cresceu $86,70 \%$.

Quadro 1 - Crescimento populacional das cidades de Brasília, Goiânia e Anápolis (1970 a 2010)

\begin{tabular}{|l|c|c|c|c|c|}
\hline \multicolumn{1}{|c|}{ Cidade } & 1970 & 1980 & 1991 & \multicolumn{1}{c|}{2000} & 2010 \\
\hline Brasília & 537.492 & 1.176 .908 & 1.601 .094 & 2.051 .146 & 2.469 .489 \\
Goiânia & 380.773 & 717.519 & 922.222 & 1.093 .007 & 1.256 .514 \\
Anápolis & 105.029 & 180.012 & 239.378 & 288.085 & 324.303 \\
\hline
\end{tabular}

Fonte: Censos Demográficos IBGE. 
Quadro 2 - Crescimento populacional do arranjo espacial

Brasília-Goiânia-Anápolis (1970 a 2010)

\begin{tabular}{|l|c|c|r|r|r|}
\hline \multicolumn{1}{|c|}{ Arranjo } & 1970 & 1980 & 1991 & 2000 & 2010 \\
\hline Ride DF/GO/MG & 761.961 & 1.520 .026 & 2.161 .709 & 2.958 .196 & 3.574 .040 \\
RM Goiânia & 509.570 & 897.382 & 1.312 .739 & 1.743 .297 & 2.103 .083 \\
MR Anápolis & 250.014 & 307.664 & 352.080 & 408.484 & 466.792 \\
\hline
\end{tabular}

Fonte: Censos Demográficos IBGE.

\section{A nova dinâmica econômica do Centro-Oeste brasileiro: 0 agronegócio}

Não restam dúvidas da importância de Brasília para a transformação e o desenvolvimento do Centro-Oeste. Além de tornar a região o centro das decisões políticas e administrativas do País, possibilitou sua integração por meio de uma malha de rodovias que surgiram no intuito de ligar a nova capital federal às demais regiões brasileiras. Não apenas essa rede de transportes, mas também as diversas políticas públicas federais que surgiram após a mudança da capital favoreceram as diversas alterações no quadro econômico e social da região.

\section{0 surgimento de uma nova dinâmica econômica do Centro-Oeste}

A partir da década de 1930, o Estado brasileiro foi o grande organizador da acumulação industrial, instituindo políticas de caráter nacional, e promotor da integração do mercado interno, tornando-se o responsável maior pela abertura e ampliação das fronteiras de acumulação.
Os efeitos dinamizadores desse novo modelo de desenvolvimento tiveram impactos significativos na história econômica brasileira e em especial na região Centro-Oeste, pois a demanda por alimentos foi estimulada pela ampliação do mercado interno e pela intensificação do setor industrial. Assim, ampliaram-se os vínculos das regiões mais desenvolvidas, como o Sul e Sudeste, com as áreas de produção agropecuária. Esse fator motivou a implantação das políticas nacionais de colonização, cujo exemplo pioneiro foi a Marcha para o Oeste.

No caso específico do Centro-Oeste, as políticas propostas pelo Estado nacional sobrepuseram à formação econômica e social que fora constituída durante o período da mineração, agricultura e pecuária extensivas, já existentes no território, fazendo com que a região passasse a ter maior presença no cenário nacional. Seu perfil, tanto físico-territorial como produtivo, foi gradativamente sofrendo alterações, na medida em que a oferta elástica de terras estimulava a penetração de colonos do Sul e Sudeste e também de estrangeiros, como alemães e japoneses.

Após o declínio da mineração, a região se configurou como produtora nos setores de pecuária (corte e leite) e agricultura (alimentos 
básicos) extensivas. Mais recentemente, a tem se tornado a grande produtora de grãos do Brasil (sobretudo soja e milho); além de abrigar várias agroindústrias e algumas consideráveis experiências isoladas de indústrias com maior necessidade de uso de tecnologias, como a farmacêutica e a automobilística.

Com o avanço da economia cafeeira de São Paulo, as transformações na região tiveram impulso pela necessidade de incorporar novas áreas para abrir novas rotas de penetração. $A$ ferrovia foi decisiva para impulsionar tal dinâmica. À medida que o Centro-Oeste foi sendo ocupado, passou também a ocupar espaço específico na divisão territorial do trabalho, como produtor de alimentos e matérias-primas para alimentar populações e a indústria do Sudeste.

A modernização das estruturas produtivas do Centro-Oeste começa a mudar a partir do final da década de 1960, marcada pelo ingresso de novos migrantes e novos produtos - sobretudo soja -, deslocando os produtos tradicionais de abertura de fronteira, como arroz, milho e feijão. Essa ocupação "moderna" promoveu a expropriação de camponeses e pequenos agricultores tradicionais, literalmente expulsando populações originais e condenando à extinção as economias naturais preexistentes. As políticas de incentivos públicos também foram decisivas nesse processo.

Assim, as décadas de 1960 e 1970 viram difundir rapidamente, sobretudo nas áreas de cerrado do Centro-Oeste, um novo modelo produtivo com práticas transformadoras da realidade até então existente. Nesse período, constituíram-se as bases para a introdução das frentes modernas, que impactaram vigorosamente a economia e a estrutura urbana, como as políticas nacionais de colonização, integração e interiorização da economia, a fundação de Brasília e a modernização das vias de transportes, das bases energéticas e das telecomunicações.

Essa intervenção do Estado brasileiro ocorreu através dos diversos programas públicos, com destaque aos constantes no I e II PND - Plano Nacional de Desenvolvimento. Eram programas de incentivos fiscais, implantação de infraestrutura básica, pesquisas agropecuárias para melhoramento dos solos dos cerrados e controle de imigrações. Como resultado, nas décadas de 1970 e 1980, o Centro-Oeste passou a apresentar crescimento populacional e produtivo mais substanciais. Importantes empresas agroindustriais de capital nacional ou estrangeiro foram para a região, transformando-a na maior produtora de alimentos do Brasil, com estrutura baseada no latifúndio e totalmente voltada para o mercado externo.

Diante das mudanças nas políticas macroeconômicas, que intensificaram a financeirização da economia e renovaram as bases produtivas, elevou-se a inserção do País na economia internacional, provocando alterações importantes nos padrões de comércio exterior e alterando as dinâmicas regionais. 0 território brasileiro recebeu diretamente os impactos de uma economia que passa a ser orientada por uma nova ordem mundial, inserindo-se de maneira passiva no processo de globalização. 0 Brasil passa a atender diretamente aos interesses do grande capital privado internacional, com uma nova estrutura econômica e um novo ordenamento territorial (Macedo, 2010).

0 Centro-Oeste, região que sofreu "involução econômica após a efervescência da mineração no século XVIII" (ibid., p. 191), foi 
inserido ativamente nesse processo. Nas duas últimas décadas vem se destacando como a região mais dinâmica do agronegócio brasileiro, concentrando produção e renda. É a segunda região brasileira em extensão territorial e em grau de urbanização, porém é a que apresenta menor densidade demográfica. Considerando que se trata de uma exploração agrícola desagregadora que, além de não gerar empregos, expulsa as pessoas do campo, "a região Centro-Oeste é a que melhor sintetiza o esforço de inserção comercial do país" (ibid., p. 190).

A chegada de novos agentes à região promoveu a substituição de antigas atividades de subsistência e economia natural por modernas produções do agronegócio internacionalizado. Tudo provocou uma completa redefinição do uso e de ocupação do solo e consequentemente a reorientação de sua organização espacial (ibid.). Assim, o território do Centro-Oeste deixa de ser usado para o plantio extensivo de lavouras ou pastagens e dá lugar a uma nova lavoura rica em técnicas. A terra passa a ficar mais concentrada e valorizada, e a produção cresce gradualmente ano a ano, de forma tão extraordinária quanto o seu crescimento demográfico, queconfirma o caráter produtivo da região. De 1965 até 2010, a região elevou sua área de plantio de pouco mais de 2 milhões para 16 milhões de hectares (Quadro 3).

Em 1965, o Centro-Oeste participava com $6,8 \%$ das áreas plantadas no território brasileiro. Proporção que se eleva para 25,3\% em 2010. Percebe-se que esse crescimento da área plantada no Centro-Oeste se centrou em um único produto: as tradicionais lavouras de arroz. Utilizadas para a ampliação da fronteira agrícola, essas lavouras ofereciam o principal produto da pauta produtiva do Centro-Oeste. Mas, com a intensificação da agricultura de exportação, implantada sobretudo nas décadas de 1980 e 1990, elas perderam espaço para a lavoura da soja, produto mais valorizado no mercado internacional (Quadro 4).

\section{Quadro 3 - Área colhida na Região Centro-Oeste e Brasil 1965 a 2010 (por hectares)}

\begin{tabular}{|l|r|r|r|r|r|}
\hline \multicolumn{1}{|c|}{ Estado / Região } & \multicolumn{1}{c|}{1965} & \multicolumn{1}{c|}{1980} & \multicolumn{1}{c|}{1990} & \multicolumn{1}{c|}{2000} & \multicolumn{1}{c|}{2010} \\
\hline Distrito Federal & 6.770 & 26.868 & 89.227 & 84.690 & 121.989 \\
Goiás & 1.584 .762 & 2.202 .921 & 2.527 .421 & 3.080 .405 & 4.446 .308 \\
Mato Grosso do Sul & & 1.740 .011 & 2.041 .128 & 1.863 .740 & 3.040 .623 \\
Mato Grosso & & 1.209 .343 & 2.476 .614 & 4.811 .557 & 8.753 .926 \\
Centro-Oeste & 2.212 .887 & 5.179 .143 & 7.134 .390 & 9.840 .392 & 16.362 .846 \\
Brasil & 32.521 .457 & 49.517 .480 & 50.514 .696 & 50.197 .379 & 64.450 .342 \\
\hline
\end{tabular}

Fonte: Ipeadata. 
Quadro 4 - Área colhida pelos principais produtos agrícolas do Centro-Oeste 1965 a 2010

\begin{tabular}{|l|r|r|r|r|r|}
\hline \multicolumn{1}{|c|}{ Produto } & \multicolumn{1}{c|}{1965} & \multicolumn{1}{c|}{1980} & 1990 & \multicolumn{1}{c|}{2000} & 2010 \\
\hline Arroz & 1.174 .222 & 2.367 .091 & 772.771 & 915.649 & 417.378 \\
Cana de açúcar & 43.519 & 49.505 & 215.983 & 373.396 & 1.023 .738 \\
Milho & 514.829 & 941.123 & 1.416 .480 & 1.803 .292 & 3.431 .652 \\
Soja & 804 & 1.130 .093 & 3.810 .153 & 5.530 .455 & 9.861 .994 \\
Algodão & 69.342 & 80.295 & 123.451 & 403.730 & 449.129 \\
\hline
\end{tabular}

Fonte: Ipeadata.

Todo esse processo produtivo, seja via produção ou processamento de alimentos, fez elevar também as atividades voltadas para a prestação de serviços, devido à grande movimentação promovida pelo agronegócio. A crescente industrialização, sobretudo no estado de Goiás, o forte comércio, particularmente em Goiânia e Anápolis, e os serviços públicos em Brasília também são fatores que em muito contribuíram para a elevação do setor de serviços. Porém, a lógica atual de inserção externa, que fez do Centro-Oeste o grande exportador brasileiro, mantém a economia da região fortemente pautada na venda de produtos primários para o exterior.

\section{Os impactos do agronegócio no ambiente urbano do arranjo}

Ao longo da primeira década dos anos 2000, o mercado imobiliário brasileiro experimentou intenso período de expansão. Esse movimento, que se iniciou timidamente na década anterior, principalmente pós Plano Real, teve seu auge entre 2001 e 2007.
Tal realidade foi fortemente percebida no arranjo Brasília-Anápolis-Goiânia. Como essas cidades exercem centralidade no desenvolvimento econômico do Planalto Central brasileiro, naturalmente receberam grandes investimentos em empreendimentos imobiliários, devido à alta concentração de população consumidora de imóveis.

Nos últimos dez anos, o setor imobiliário dessas cidades passou por inovações da gestão empresarial dos negócios. Nesse período novas formas de atuação foram introduzidas na indústria da construção civil local, fortemente marcada pela entrada de capital externo que se funde com grandes grupos nacionais e locais. Surgiram, assim, diversos empreendimentos voltados para o consumidor de nível mais elevado (Moysés e Borges, 2009).

Todos os novos empreendimentos que surgiram em áreas de expansão das cidades, seja em Águas Claras, Sudoeste, Lago Norte ou Noroeste, regiões administrativas de Brasília, seja no Setor Bueno, Parque Flamboyant, Alto da Glória ou Jardim Goiás, em Goiânia, ou no Bairro Jundiaí, em Anápolis, obtiveram grande êxito de vendas, com os empreendimentos 
tendo $98 \%$ de suas unidades vendidas na mesma semana de lançamento da obra, conforme informação das entidades que representam o setor imobiliário, como Secovi (Sindicato da Habitação do Estado de Goiás) e Ademi (Associação das Empresas do Mercado imobiliário de Goiás). Trata-se de empreendimentos caros, dotados de completa infraestrutura, conforme os novos conceitos de cidade construída para atender às classes mais abastadas da sociedade local.

Tanto Goiânia como Brasília cresceram para além do seu território planejado. Esse fato, bastante comum em muitas capitais, não foi previsto no planejamento dessas cidades. No caso de Brasília, seu formato de cruz limita a quantidade de unidades para habitação. Como as cidades-satélites ficam distantes do Plano Piloto e as mais próximas, como Taguatinga e Guará, rapidamente se esgotaram, foi preciso abrir novas áreas para a expansão imobiliária, como os Lagos Sul e Norte, o Sudoeste e, mais recentemente, o Noroeste. Todos esses novos "bairros" da capital federal são habitados por população de elevado padrão de renda, que se nega a residir em lugares mais distantes.

Em Anápolis, a única das cidades não planejada, portanto sem limites para seu crescimento, é onde possivelmente reside uma população mais tradicional que a de Brasília e Goiânia. Os grandes empreendimentos imobiliários chegaram mais tarde, basicamente após 2006, quando grandes investimentos passaram a provocar alterações fundamentais na paisagem local.

Ao contrário de Brasília, que surgiu com áreas valorizadas pelo próprio desenho urbano, Goiânia foi direcionando a ocupação e valorizando seu território a partir da implantação de equipamentos. 0 primeiro Plano Diretor (1969) definiu os vetores para o desenvolvimento da cidade, limitando seu crescimento, de maneira a mantê-lo ordenado. A expansão urbana deveria direcionar-se a norte, ao longo do Rio Meia Ponte, e a leste, ao longo da BR-153. A cidade poderia crescer para o sudoeste, e a estrutura viária seria realizada pelos eixos leste-oeste e norte-sul. Esses preceitos só ocorreram em partes. A construção de viadutos na BR 153 permitiu que a cidade expandisse muito para o leste.

As obras no perímetro urbano da BR 153/060 atenderam a exigências da nova dinâmica que a região leste da cidade passou a enfrentar a partir de 1981. A implantação do Shopping Flamboyant, às margens dessa rodovia, começou a alterar a dinâmica dos bairros adjacentes, como Alto da Glória e Jardim Goiás. Esse shopping, o primeiro de grande porte do estado de Goiás e segundo do Centro-Oeste, ${ }^{3}$ favoreceu a valorização das terras dessa região da cidade, pertencentes a um único proprietário, que também foi o fundador do shopping. $A$ movimentação desse centro de compras atraiu para as proximidades lojas de grandes redes varejistas, e a região, hoje, detém grande centralidade e passa por constantes transformações. ${ }^{4}$ Após a chegada do comércio, instalaram-se na região condomínios residenciais verticais, de alto padrão, e em seguida condomínios horizontais fechados, tanto de capital local como externo. Nessa região, pratica-se o metro quadrado mais valorizado da Região Metropolitana, representando grande status para quem nela reside.

Ações do poder público favoreceram essa dinâmica e sua consequente valorização. $\mathrm{Na}$ década de 1970, foram implantados, na região, o Estádio Serra Dourada e o Autódromo da 
Cidade. ${ }^{5}$ Depois disso, vieram os investimentos privados, como o shopping e os condomínios residenciais e comerciais. A partir de 2006, novas intervenções públicas voltaram a acontecer, elevando ainda mais sua valorização. A primeira foi do governo estadual, que inaugurou, no trevo da BR 153/060 com a GO 020, o Centro Cultural Oscar Niemeyer, em 2006. Em 2009, a prefeitura inaugurou, não muito distante dali, o Parque Flamboyant, o que permitiu a construção, em seus arredores, dos apartamentos mais valorizados da cidade.

É nas imediações dessa região sudeste de Goiânia que se localiza o maior número de condomínios horizontais fechados de toda a RM. E os mais valorizados também. A expansão do perímetro urbano acabou tendo que ser aprovada para acompanhar essa demanda existente por novas áreas para a instalação de mais condomínios residenciais. 0 caso mais bizarro ocorreu no Plano Diretor de 2006, quando, para incluir uma área onde seria instalado o suntuoso condômino Goiânia Golf Residence, fez-se um "apêndice" no mapa da cidade. Essa área ficou conectada ao restante da zona urbana apenas pela linha que demarca uma rodovia municipal; literalmente, pendurada à zona urbana.

A maioria desses empreendimentos, na região Sudeste de Goiânia, foi lançada por incorporadores locais, nacionais ou estrangeiros, em parceria com a família proprietária das áreas. Ou seja, pelo mesmo proprietário do shopping, que já havia, anteriormente, "cedido" terras para a implantação de grandes equipamentos urbanos. Não restam dúvidas de que se trata do maior latifúndio urbano da história da cidade.
0 bom desempenho e a preocupação com a saturação da ocupação dessa área acabaram por favorecer a abertura de novas frentes de expansão e valorização imobiliária em outras regiões de Goiânia. São bons exemplosa região do Parque Vaca Brava, a partir de 1996, e do Parque Cascavel e do Macambira Anicuns, a partir de 2009, todas elas na porção centro-oeste da cidade. A partir de 2013, foi inaugurado outro grande shopping na região norte, pertencente ao maior grupo industrial de Portugal, em sociedade com empresários estadunidenses. 0 empreendimento está alterando a configuração da área, até então uma das menos valorizadas, e levando o poder local a tomar inciativas para acompanhar essa transformação, como a abertura de grandes avenidas (caso da ampliação da Goiás Norte, pela prefeitura) e instalação de viadutos (como os da Perimetral Norte, pelo governo estadual).

Em 2013 a prefeitura municipal enviou à Câmara de Vereadores projeto de lei para expandir mais ainda o perímetro urbano de Goiânia, no sentido norte. Esta é a única região da cidade que ainda não se encontra totalmente na zona urbana e onde estão as reservas florestais e o reservatório de águas que abastece a região metropolitana. Daí o motivo de tal projeto ter gerado grande polêmica e ainda não ter sido viabilizado.

Já a região sul da cidade desenvolveu-se bem antes. Por ter se conurbado a Aparecida de Goiânia, segundo maior município da RM e de Goiás, os empreendimentos imobiliários ali se instalaram principalmente no final da década de 1990, quando também se instalou um shopping. Desde então, essa região se tornou alvo de especulação e investimentos 
imobiliários tão vultosos como os da região sudeste. Porém, os empreendimentos da região sul não são voltados para as classes mais ricas. Nessa região, alto do Setor Bueno, entorno da Avenida Rio Verde, Parque Amazônia, habita uma população classe média a média alta, e a região está altamente verticalizada.

Conforme a prefeitura de Goiânia, entre 2000 e 2011, foram construídos na cidade 423 condomínios habitacionais (denominados "habitação coletiva"). Destes, 187 (44\%) eram voltados para moradores de "alto padrão" e se localizam em bairros mais valorizados. Mais recentemente, houve o aumento da construção de edifícios, sobretudo residenciais, em bairros antes tradicionalmente horizontais, como Negão de Lima, Nova Vila e Leste Universitário. Esses bairros ficam na região centro-leste da cidade e próximos da BR 153/060 ou da Perimetral Norte. Sem condição de habitar um imóvel de "alto padrão" na valorizada região sudeste, essa população encontra essas alternativas mais acessíveis também às margens da rodovia. Toda essa oferta habitacional atrai como moradores pessoas que precisam se deslocar entre as cidades da RM e para além de seus limites, como Aparecida de Goiânia, Senador Canedo e principalmente Anápolis. Dá origem a uma multiplicidade de fluxos - muitos realizando comutação cotidiana - que articulam o arranjo sob um novo tipo de integração entre espaços polinucleados.

0 mercado imobiliário, como qualquer outro mercado, acompanha as demandas da população pela busca de qualidade. Para isso, adapta-se às novas tendências e aos novos estilos de consumir. A alta renda gerada pelo agronegócio e a migração crescente de pessoas que vão para a região, levadas pelos novos negócios que surgem constantemente, favorecem essa efervescência imobiliária. Ao mesmo tempo, a demanda por menor rendimento amplia as áreas de expansão das cidades.

Brasília tem sua dinâmica própria de capital federal. Concentra a sede de grandes empresas nacionais (públicas ou privadas), grande número de funcionários públicos que, em geral, possuem alta renda. Tudo isso faz com que 0 Distrito Federal (DF) tenha um terciário forte, gerando riquezas, empregos e atraindo cada vez mais trabalhadores e consumidores. Quem possui renda melhor adquire um apartamento, no Plano Piloto (Asas Sul ou Norte), em Águas Claras, Sudoeste, Noroeste, ou uma casa nos Lagos. Quem não tem mora nas cidades-satélites dentro do próprio DF. Os mais desprovidos moram em Goiás, na região conhecida como Entrono do DF, que é detentora de graves problemas socioespaciais.

Nota-se que o Distrito Federal tem sofrido perda, cada vez maior, de população para os municípios vizinhos goianos. Entre 1970 e 1980, a população do DF cresceu 8,15\%; entre 1980 e 1991, 2,84\%; entre 1991 e 2000, 3\%; e, entre 2000 e 2010, 1,81\%, sendo este o menor crescimento registrado na história do DF. Nesse período, a microrregião goiana do Entorno do DF foi uma das que mais cresceu, conforme o IBGE. Entre 1991 e 2000, aumentou sua população em 72,55\% e, entre 2000 e 2010, aumentou 29\%. Porém, esses municípios goianos acabam por se tornar apenas "cidades-dormitório". Essa população, afugentada pelo alto preço da terra do DF e que passou a residir em Goiás, em municípios com pouca infraestrutura, continua trabalhando e desempenhando suas principais atividades cotidianas no DF, tornando a mobilidade uma necessidade essencial. 
As pressões por moradias populares no DF são crescentes, elevando as ocupações irregulares. No início do planejamento do DF, foram destinadas nas cidades-satélites áreas para assentar a população que não tivesse condição para ocupar o Plano Piloto. Anos depois o Governo do Distrito Federal (GDF) continuou com esses programas, que, entre 1989 e 1994, deram origem às regiões administrativas de Paranoá, Santa Maria e Samambaia. Eram regiões distantes do Plano Piloto. Para os mais ricos, o GDF criou o Sudoeste, praticamente anexo à Asa Sul - separados apenas pelo Parque da Cidade e Águas Claras, anexo a Taguatinga e não tão distante da Asa Sul. Hoje essas regiões se encontram totalmente ocupadas. Mesmo Samambaia, que de início era voltada para baixa renda, experimenta uma verticalização que tem alterado completamente 0 ambiente. Até meados dos anos 2000, ela poderia ser comparada a uma favela. Localizada bem na entrada de Brasília, para quem chega de Goiânia ou Anápolis, sua arquitetura era basicamente composta por casebres de papelão ou madeira, cobertos de palha ou telha de amianto, e o que mais chamava a atenção era 0 amontoado de fios elétricos e antenas de TV. Hoje o cenário é completamente diferente. A entrada do empreendedorismo imobiliário em Samambaia afastou a população pobre e alterou o estilo arquitetônico do bairro, tornando-o praticamente uma extensão dos valorizados Águas Claras e Taguatinga.

Mais recentemente, nota-se a formação de uma nova expansão urbana no DF, também em direção a Goiás. Uma nova conurbação, ao longo da BR 040, tende a se formar entre Santa Maria (DF), Valparaíso de Goiás, Novo Gama e
Cidade Ocidental, todas goianas. Pela BR 060, a expansão de Samambaia tende a se unir com Ceilândia (DF), ultrapassar os limites do DF e alcançar Águas Lindas de Goiás, que é umas das cidades que apresentou o mais elevado crescimento demográfico nas últimas décadas. Os empreendimentos que surgem na BR 040 são mais populares, como os decorrentes do Programa Minha Casa Minha Vida, voltados para segmentos de baixa renda ou de classe média. Na BR 060, surgem os condomínios de alto padrão.

Pode-se afirmar que uma das forças que impulsiona a expansão e o mercado imobiliário do DF é a presença de funcionários públicos de renda elevada, ligados ao Governo Federal, como também de executivos de empresas terceirizadas. Pelo fato de Brasília concentrar um relevante polo de serviços, também estimula os produtores rurais, assim como ocorre em Goiânia, a buscarem a capital federal como um bom lugar para residência de suas famílias e, com isso, trazem para seu território a renda do agronegócio.

Isso é mais antigo em Goiânia, onde a dinâmica já é toda voltada para a lógica do agronegócio. Inicialmente a cidade era habitada por fazendeiros locais; proprietários que, mesmo possuindo fazendas no interior do Estado ou no Pará, Mato Grosso ou Tocantins, viviam em Goiânia com suas famílias. Assim, a renda gerada nas fazendas era empregada na cidade, desenvolvendo nela o setor de serviços, fundamentalmente educacional e de saúde, e o comércio varejista, e tornando-a referência para grande parte do centro-norte brasileiro. Assim, Goiânia tornou-se uma forte centralidade com grande região de influência. Hoje, os ricos 
pecuaristas goianos são os investidores do setor imobiliário local, seja na aquisição de imóveis seja na parceria com os capitais externos.

Também em Goiânia houve valorização da terra, e o crescimento dos empreendimentos voltados às pessoas de maior renda fez com que a classe média se afugentasse para os arredores da cidade. Aparecida de Goiânia e Senador Canedo foram os municípios que mais receberam população e igualmente podem ser enquadrados como "cidades-dormitório". A valorização do preço da terra na capital permitiu que famílias comprassem dois ou mais imóveis em áreas menos valorizadas e elevassem o patrimônio familiar. Dessa maneira, cresceram os centros menores ao redor de Goiânia, como ocorreu em Brasília.

Anápolis possui dinâmica diferente, mesmo tendo seu perímetro urbano em contínua valorização, pois a cidade sempre apresentou forte posição comercial. A instalação de novas indústrias e mais recentemente os preparativos para a implantação da Plataforma Logística Multimodal de Goiás atraíram nova leva de migrantes, ampliando a demanda por áreas de moradia, aumentando ainda mais os preços da terra e fazendo surgir na cidade uma verticalização que não era vista até meados da década passada.

Tanto em Goiânia como em Anápolis ou Brasília, a pujança do mercado imobiliário, motivada pela renda das fazendas das famílias locais, agora inseridas na lógica do agronegócio, a chegada de novas empresas e a abertura de novos postos de trabalho públicos têm levado à região novos hábitos e tendências de morar, alterando a mentalidade local e mantendo elevado o preço da terra. Um novo urbano surgiu nessas cidades e modificou cada vez mais suas realidades. Ademais, desencadeou um efeito dominó de valorização do solo e de desbravamento de novas periferias, dando maior densidade e estendendo a continuidade da área construída que interliga essas aglomerações e dá o conteúdo de uma unidade espacial.

Observa-se, na análise dessas três aglomerações altamente urbanizadas, que 0 empreendedorismo urbano, considerado um importante negócio capitalista, passou a administrar as cidades como se fossem empresas, tornando secundários os interesses apenas locais em função de se tornarem negócios globais; a serem vendidas como mercadoria, "sobretudo uma mercadoria de luxo, destinada a um grupo de elite de potenciais compradores: capital internacional, visitantes e usuários solúveis" (Vainer, 2000, p. 83). Como mercadoria, a cidade passa a buscar maior competitividade na atração de investimentos públicos e privados, que sejam capazes de torná-la um espaço "eficiente" para a propagação e reprodução do capital. Os agentes privados, atuando com respaldo da política urbana praticada nas cidades, são os maiores beneficiados dessa realidade. Novos espaços se tornam, cada vez mais, subordinados à dinâmica imposta pelo mercado imobiliário.

Esse processo de reprodução do espaço pode parecer contraditório com o sentido no qual Goiânia e Brasília foram planejadas - dentro dos pressupostos da cidade ideal. Porém, no sistema capitalista, mesmo uma cidade planejada não está isenta de sofrer as interferências de um urbanismo guiado por ações políticas, econômicas e técnicas. 0 território urbano é fragmentando, tornando o local de habitar um 
"fetiche", definindo, desse modo, a relação social entre coisas, mais real do que entre homens (Marx, 2006).

Nas cidades analisadas, as administrações atuam na promoção da imagem de "eficiência administrativa" (Compans, 2005), o que favorece uma enorme adesão social a esse modelo de gestão do urbano (Sánchez, 2003). Tal modelo de empreendedorismo urbano apontado nas cidades analisadas - impulsiona o surgimento de uma hierarquia de espaços na cidade, qualificados pela dotação de investimentos públicos e privados, favorecendo 0 surgimento de um terciário qualificado e, paralelamente, de especificidades no modo de viver dos habitantes (Borja, 1997). Hierarquização da cidade que cria uma fragmentação, pois gera valorização diferenciada para cada parte dos espaços urbanos, pautada pelo padrão de consumo (Harvey, 2005).

\section{Morfologias expandidas e o debate teórico e conceitual}

A dinâmica de expansão da ocupação urbana, com a presença de capitais do setor imobiliário externos à região, e o desbravamento de novas áreas, distantes das já consolidadas, para construção de unidades para diversos segmentos de renda, caracterizam o modo capitalista de produção do espaço urbano na contemporaneidade. Elemento fundamental nesse processo são as vias de circulação - rodovias ou vias urbanas - e o massivo uso do automóvel para garantir a conexão entre 0 lugar da moradia, do trabalho e do consumo.
Nas aglomerações metropolitanas de Brasília e de Goiânia e na própria cidade de Anápolis, esse modelo se apresenta com todas as suas peculiaridades, estreita continuamente o fluxo de relações entre elas e as faz inserir-se em um arranjo espacial.

Na contemporaneidade, a expansão da ocupação urbana apresenta características de diversificação socioeconômica, porém segue associada ao valor da terra e a projetos imobiliários altamente especulativos, com as áreas incorporadas demarcando uma expansão periférica, permeada por vazios urbanos mantidos como reservas de valor. Consolida-se a partir da ação dos vários capitais, com ênfase no imobiliário, pela dispersão ou relocalização de atividades econômicas e expansão da ocupação residencial, que, no caso brasileiro, associa grandes condomínios fechados ou conjuntos habitacionais de baixa renda a ocupações informais nas franjas das cidades, resultantes da segregação e da exclusão dos mercados formais de moradia.

São relevantes a distância cada vez maior das novas ocupações e a elevação da mobilidade, não só no interior dos aglomerados, criando laços de interação entre eles. No debate teórico atual, essa transformação - metamorfose para alguns autores (Lencioni, 2011; De Mattos, 2014) - pela qual passa o espaço urbano se funda na ampliação geográfica do processo de acumulação desse estágio do capitalismo. Uma ampliação que induz a formação de morfologias urbanas descontínuas, dispersas, sem limites precisos, porém muito mais articuladas e densas. Essas morfologias são engendradas pela dispersão de processos produtivos, empresas, filiais, fornecedores, que acionam o capital 
imobiliário a ativar negócios na produção imobiliária, e de infraestruturas indispensáveis à valorização do espaço urbano.

Abre-se, pois, um novo ciclo capaz de enfrentar as contradições que comprometem a reprodução do capital, fundado na importância dos negócios oriundos da produção imobiliária e das condições de infraestruturas indispensáveis para que se efetivem a metropolização e a valorização do espaço metropolitano.

A forma que a metrópole assume, de maior escala territorial, ao expandir sua região, é central para a acumulação porque ela vem acompanhada da possibilidade de oferecer sobrevida às relações capitalistas, uma vez que a valorização imobiliária que acompanha o espraiamento territorial da metrópole se constituiu numa das principais estratégias para a produção e concentração da riqueza social, uma vez que o predomínio da descontinuidade é estratégico para a reprodução do capital. A sua forma descontínua, por assim dizer, é a expressão, no limite último, da força desmedida do espaço-mercadoria, instrumentalizado pela valorização imobiliária do capital. [Essa] se coloca como possibilidade de [...] superar o estrangulamento que pode comprometer o fôlego necessário para dar continuidade ao processo capitalista de desenvolvimento. (Lencioni, 2011, pp. 55-56)

Essas aglomerações "espichadas" ao longo das vias de circulação, quando próximas, desenvolvem intensa conexão entre si, estimulando a alocação, nas vias de interligação, de serviços e posteriormente de novas áreas de moradia, consumo e lazer. Em pouco tempo dão lugar a arranjos espaciais característicos do processo de metropolização contemporâneo. Esse processo vem sendo objeto de reflexão nos vários continentes (Ciccolella e Vecslir, 2010; De Mattos, 2014; Lencioni, 2011; Pradilla Cobos et al., 2010; Scott et al., 2001).

Alguns aspectos particulares demarcam o caso brasileiro. 0 padrão de expansão dos aglomerados urbanos em direção a áreas adjacentes, interconectando pequenos centros pree-existentes e integrando seus territórios graças a novas capacidades comunicacionais, configura desde simples eixos bipolarizados até complexos macrometropolitanos. 0 arranjo Brasília-Anápolis-Goiânia encontra completa consonância com as análises e considerações teóricas sobre os processos contemporâneos da metropolização, com forte presença do capital imobiliário nas configurações morfológicas urbanas e dos aglomerados. Porém, observa-se nele um peso ainda mais expressivo da ação do Estado (seja por meio de investimentos, seja pela adequação normativa), como indutor da expansão urbana e regional, e uma crescente oferta de consumidores de novas áreas urbanas, particularmente associada ao entorno, dedicado ao agronegócio - gerador de elevados excedentes.

Haddad (2011), em sua dissertação sobre o recorte objeto de análise, o denomina "eixo Goiânia-Anápolis-Brasília", considerando a relação entre espaço e transportes. Admite que, desde a escola clássica da análise espacial, representada por Von Thunen, Losch, Weber e outros, atribui-se ao transporte e à acessibilidade a função de definir e explicar configurações territoriais. Perroux (1964), ao tratar do conceito de polos de desenvolvimento, afirma que eles não existem de forma isolada, mas se ligam à sua região por canais em que se propagam preços, fluxos e antecipações. Essa propagação dá origem ao que ele chama de eixo de 
desenvolvimento, salientando que o eixo não é apenas uma estrada, mas que, "ligado à estra$\mathrm{da}$, deve haver todo um conjunto de atividades complexas que indicam orientações determinadas e duráveis de desenvolvimento territorial e dependem, sobretudo, da capacidade de investimento adicional" (Andrade, 1987, p. 66).

Tanto na visão de Perroux como de vários outros autores, ${ }^{6}$ um eixo não pode prescindir de bens que o complementem, como energia, transporte, crédito e capacidade técnica. Não é apenas uma estrada, mas pressupõe determinado corte espacial, com a presença de um conjunto de atividades complexas que indicam desenvolvimento territorial. Portanto, pode-se afirmar que um eixo de desenvolvimento surge em um espaço onde estejam presentes: uma cadeia de núcleos urbanos, de diferentes tamanhos, situados ao longo das vias de transporte; vias de transporte de alta capacidade, como rodovias duplicadas, ferrovias modernas e infovias; cabos de fibra ópticas, telefonia, rede de computadores; e um sistema de transporte adequado, que favoreça a dinâmica econômica dos centros urbanos, principalmente no tocante à localização das mais diversas atividades industriais. Todas essas leituras destacadas se ajustam à noção do arranjo espacial, que incorpora a noção de eixo e que se materializa no recorte espacial analisado.

Ajustam-se também à concepção de cidade-região (Scott et al., 2001), que faz referência a uma categoria espacial que absorve desde aglomerações metropolitanas comuns, dominadas por um núcleo muito desenvolvido, até unidades geográficas policêntricas, compondo territórios diversos e desiguais, morfologias que transcendem espacialmente o âmbito urbano compacto ou disperso e que exigem estratégias que potencializem o desenvolvimento. Funcionam como atores decisivos do novo fenômeno de desenvolvimento, com influência crescente no mundo globalizado. Lencioni (2006) aplica a expressão cidade-região para o caso do complexo macrometropolitano de São Paulo; Soares (2012), para a articulação da aglomeração metropolitana de Porto Alegre às aglomerações urbanas circunvizinhas.

Especificamente em relação ao caso brasileiro, Moura e Lira (2011) identificaram um conjunto de configurações expandidas e articuladas ou "arranjos espaciais". São arranjos diversos que compõem, desde simples aglomerações urbanas interconectadas, até aglomerações metropolitanas expandidas descontinuamente em direção a aglomerações urbanas ou a outras aglomerações metropolitanas, algumas conformando eixos, como o recorte em análise neste trabalho. Os autores apontam que esses arranjos se estruturam cada vez mais a partir de relações em rede, sob múltiplas escalas e muitos sujeitos atuantes, e pela convergência das relações verticais e horizontais, que provocam uma forte hibridização da condição urbana e regional. Assim, extrapolam a dimensão da cidade e da aglomeração e incorporam, no mesmo fato urbano-metropolitano, a dimensão regional, o que torna sua natureza complexa e peculiar (Moura, 2009). Nesse sentido, há um entrecruzamento entre as noções de unidades concentradoras formadas por aglomerações urbanas ou metropolitanas, em sua versão descontínua e fortemente estruturada por eixos de circulação que garantem comutação e conectividade, e a noção de desenvolvimento regional, para a qual a configuração axial articulando aglomerações vem se tornando objeto de análise da economia. 
0 arranjo Brasília-Anápolis-Goiânia insere-se entre aqueles apontados com natureza urbano-regional, pois se caracteriza como unidade concentradora de população, relevância econômico-social e infraestrutura científico-tecnológica, com elevada densidade urbana, forte articulação regional e extrema complexidade, devido à rede de fluxos multidirecionais, particularmente de pessoas, e pela multiplicidade escalar. Participa de modo mais integrado, nos âmbitos estadual, nacional e internacional, como elo de inserção nos estágios mais avançados da divisão social do trabalho e representa o principal centro de decisão política e institucional do País. Nele, os padrões de expansão, com forte presença dos excedentes gerados pelo agronegócio regional, cada vez mais consolidam as características descritas pela teoria e aproximam a configuração espacial resultante de uma grande região urbana com ampla extensão territorial no Planalto Central do Brasil.

\section{Considerações finais}

A análise realizada detalha o processo de expansão urbana e a valorização de três cidades e suas aglomerações, Anápolis, Brasília e Goiânia, e mostra que suas dinâmicas correspondem a um processo comum, presente no modo de produção capitalista da cidade. Avança nesse entendimento ao mostrar que esse processo de expansão articula as três aglomerações e condiz com um novo momento de reprodução e acumulação do capital, que vem dando origem a uma urbanização muito mais estendida, formatada em arranjos complexos.

0 arranjo em análise corresponde à porção mais concentradora e com melhor desempenho econômico e social do Centro-Oeste brasileiro, que sustenta a divisão social do trabalho em sua perspectiva hegemônica. Alguns municípios foram beneficiados pela inversão de capitais (estatais e privados), enquanto outros, longe de se qualificarem em condições técnicas, científicas, institucionais e culturais para participar dessa dinâmica e contribuir no processo de transformação, permanecem à margem do processo. Tal comportamento reforça a hipótese de que a presença do Estado foi imprescindível para a sustentação do desenvolvimento regional, e que se tornam necessários grandes empreendimentos sociais e de infraestrutura situados fora do âmbito da iniciativa do mercado para conquistar maior igualdade entre os municípios.

A dinâmica do agronegócio no Centro-Oeste, especialmente no estado de Goiás, e os empregos gerados pelo governo no Distrito Federal fizeram nascer um terciário qualificado que atraiu para a região moradores de alto padrão, impulsionando a oferta de imóveis, serviços e equipamentos comerciais que promoveram a expansão da área ocupada e a valorização do solo. Pode-se inferir que o antigo capital rural acabou reproduzindo e se tornando o capital investidor de novos imóveis que, associado ao capital externo, mudam o cenário e o modo de habitar nessas cidades. 0 local de morar tornou-se símbolo de status. 0 poder público, por sua vez, propiciou ou permitiu que a iniciativa privada provesse os grandes equipamentos que valorizaram o espaço urbano, atraindo consumidores cada vez mais exigentes.

É certo que nem só esses novos moradores consomem nessas cidades. A diversificação da oferta de moradias, para vários padrões de 
renda e diferentes perfis de consumo, também se faz presente na expansão periférica e na formação de cidades-dormitório nas metrópoles analisadas. Conclui-se que a riqueza gerada no entorno vem induzindo a qualificação e valorização dos espaços urbanos, sem romper as condições de desigualdade existentes, pelo contrário, acentuando-as ao criar espaços cada vez mais fragmentados.

Ao mesmo tempo, essa riqueza é um dos elementos a impulsionar a própria configuração do arranjo espacial, pois ativa a inversão de capitais e estimula a circulação e a mobilidade entre os centros, articulando-os espacialmente em uma unidade, fortalecida pelas várias formas de conexão e interação entre lugares, atividades e pessoas. No entanto, as várias escalas institucionais (Ride, RM, RAs, entre outras) não permitem que se produza um território, tornando muito mais complexa e desafiadora qualquer tentativa de gestão desse amplo espaço articulado.

\section{Marcos Bittar Haddad}

Companhia Metropolitana de Transportes Coletivo, Região Metropolitana de Goiânia. Goiânia, GO/Brasil.

haddad13@gmail.com

\section{Rosa Moura}

Secretaria de Assuntos Estratégicos da Presidência da República, Instituto de Pesquisa Econômica Aplicada, Programa Nacional de Pós-Doutorado. Curitiba, Paraná/Brasil. rmoura.pr@gmail.com

\section{Notas}

$\left({ }^{*}\right)$ Este artigo dá continuidade e resgata alguns conteúdos das análises sobre o arranjo urbano-regional Brasília-Anápolis-Goiânia, iniciadas e debatidas no XIII Seminário Internacional da Red Iberoamericana de Investigadores sobre Globalización y Territorio (Salvador, 2014). Foi selecionado para apresentação e publicação nos anais do 55 Congreso Internacional de Americanistas, Simpósio "Difusão do agronegócio e novas dinâmicas socioespaciais na América Latina"(San Salvador, 12 a 17 de julho de 2015).

(1) Uma discussão sobre a configuração de arranjos espaciais e uma revisão da literatura pertinente podem ser encontradas em Moura (2009).

(2) Na opinião de alguns autores, como Moraes (2006), Paviani (1991) e Gouvêa (1991), Brasília já nasceu segregando população.

(3) O primeiro shopping do Centro-Oeste é o Conjunto Nacional de Brasília, cuja construção se iniciou em 1971. 
(4) Redes como Carrefour e Walmart, ambas internacionais e Tend Tudo,capital regional, e redes nacionais de hotéis são estruturas instaladas nessa região, consolidando sua centralidade para compras, lazer e moradia.

(5) Tanto a área escolhida para a instalação do autódromo quanto a área para o estádio foram “cedidas" pela família proprietária das terras. Porém, tal cessão foi fruto de negociação com o poder público, às custas de acerto de contas de tributos devidos.

(6) Bordo (2004), Hernández (1998), Nasser (2000), Pontes (1974), Souza (1993), Sposito e Matushima (2002).

\section{Referências}

ANDRADE, M. C. de (1987). Espaço, polarização e desenvolvimento: uma introdução à economia regional. São Paulo, Atlas.

BORDO, A. (2004). Os eixos de desenvolvimento e a estruturação urbano-industrial do Estado de São Paulo, Brasil. Scripta Nova. Revista electrónica de geografía y ciencias sociales. Barcelona, Universidad de Barcelona, v. IX, n. 194 (79).

BORJA, J. (1997). “As cidades e o planejamento estratégico: uma reflexão europeia e latino-americana”. In: FISCHER, T. (org.). Cidades estratégicas. Rio de Janeiro, FGV.

CICCOLELLA, P. e VECSLIR, L. (2010). Nuevos espacios del terciario y transformación metropolitana en Buenos Aires. XI SEMINARIO INTERNACIONAL DE LA RED DE INVESTIGADORES SOBRE GLOBALIZACIÓN Y TERRITORIO. Anais. Mendoza, 28 al 30 de octubre. CD-Rom.

COMPANS, R. (2005). Empreendedorismo urbano: entre o discurso e a prática. São Paulo, Editora Unesp.

DE MATTOS, C. A. (2014). Gobernanza neoliberal, financiarización y metamorfosis urbana en el siglo XXI. XIII SEMINÁRIO INTERNACIONAL DA RED IBEROAMERICANA DE INVESTIGADORES SOBRE GLOBALIZACIÓN Y TERRITORIO (RII). Salvador, 1 a 4 de setembro. [não publicado]

ESTEVAM, L. (2004). O tempo da transformação. Goiânia, Ed. UCG/Vieira.

FREITAS, R. A. (1995). Anápolis - história, geografia, economia. Anápolis, Voga.

GOUVÊA, L. A. (1991). “A capital do controle e da segregação espacial”. In: PAVIANI, A. (org.). A conquista da cidade. Brasília, Ed. UnB.

HADDAD, M. B. (2001). Eixo Goiânia - Anápolis - Brasília: estruturação, interrupção e retomada das políticas públicas. Dissertação de Mestrado. Goiânia, Pontifícia Universidade Católica de Goiás.

HARVEY, D. (2005). A produção capitalista do espaço. São Paulo, Anablume.

HERNANDEZ, J. L. S. (1998). El eje Irún-Aveiro: Geografia de un eje de desarrollo. Salamanca, Caja Duero.

IBGE (2008). Regiões de influência das cidades. Rio de Janeiro, IBGE. (2013). Divisão urbano-regional. Rio de Janeiro, IBGE. 
LENCIONI, S. (2001). "Referências analíticas para a discussão da metamorfose metropolitana". In: LENCIONI, S.; VIDAL-KOPPMANN, S.; HIDALGO, R. e PEREIRA, P. C. X. (orgs.). Transformações sócio-territoriais nas metrópoles de Buenos Aires, São Paulo e Santiago. São Paulo, Fauusp.

(2006). "Da cidade e sua região à cidade-região". In: SILVA, J. B. da; LIMA, L. C. e ELIAS, D. (orgs.). Panorama da geografia brasileira. São Paulo, Annablume.

(2011). “Referências analíticas para a discussão da metamorfose metropolitana”. In: LENCIONI, S. et al. (orgs.). Transformações sócio-territoriais nas metrópoles de Buenos Aires, São Paulo e Santiago. São Paulo, FAUUSP.

MACEDO, F. (2010). Inserção externa e territorial: impactos do comércio exterior na dinâmica regional e urbana no Brasil (1989-2008). Tese de Livre Docência. Campinas, Universidade Estadual de Campinas.

MARX, K. (2006). O Capital: crítica da economia política. Rio de Janeiro, Civilização Brasileira.

MORAES, L. M. (2006). A segregação planejada: Goiânia, Brasília e Palmas. Goiânia, Ed. da UCG.

MOURA, R. (2009). Arranjos Urbano-Regionais no Brasil: uma análise com foco em Curitiba. Tese de Doutorado. Curitiba, Universidade Federal do Paraná. Curitiba. Disponível em: http://www. observatoriodasmetropoles.net/images/abook_file/arranjos_urbanoregionais_analise_curitiba. pdf

MOURA, R. e LIRA, S. A. (2011). Aplicação da análise exploratória espacial na identificação de configurações territoriais. Revista Brasileira de Estudos Populacionais, v. 28, n. 1, pp. 153-168.

MOYSES, A. e BORGES, E. M (2009). Dinâmica imobiliária e a nova paisagem urbana na RM de Goiânia: o impacto da produção de alto nível. XIII ENCONTRO DA ASSOCIAÇÃO NACIONAL DE PÓSGRADUAÇÃO E PESQUISA EM PLANEJAMENTO URBANO REGIONAL.

NASSER, B. (2000). Economia Regional, Desigualdade Regional no Brasil e o Estado dos Eixos Nacionais de Integração e Desenvolvimento. Revista BNDES. Rio de Janeiro, v. 7, n. 14, pp. 145-178.

PAVIANI, A. (1991). "A construção injusta do espaço urbano". In: PAVIANI, A. (org.). A conquista da cidade. Brasília, Ed. UnB.

PERROUX, F. (1964). L'économie du XXème siècle. Paris, Presses Universitaires de France.

Plano de Desenvolvimento Integrado de Goiânia (1969). Prefeitura Municipal de Goiânia, Serete S.A. Engenharia, Jorge Wilheim - Arquitetos Associados.

PONTES, B. (1974). Os centros industriais do Estado de São Paulo. Boletim Paulista de Geografia, n. 49, pp. 65-142.

PRADILLA COBOS, E.; GALVÁN, F. J. M. e MÁRQUEZ, L. (2010). Cambios económicos y morfológicos en la zona metropolitana del Valle de México. XI SEMINARIO INTERNACIONAL DE LA RED DE INVESTIGADORES SOBRE GLOBALIZACIÓN Y TERRITORIO. Mendoza, 28 al 30 de octubre. (CDRom).

SÁNCHEZ, F. (2003). A reinvenção das cidades para um mercado mundial. Chapecó, Argos.

SCOTT, A. J.; AGNEW, J.; SOJA, E. W. e STORPER, M. (2001). Cidades-regiões globais. Espaço e Debates, n. 41, pp. $11-25$. 
SOARES, P. R. (2012). Metropolización del territorio y aglomeraciones urbanas en Sur de Brasil. XII SEMINARIO INTERNACIONAL DE LA RED DE INVESTIGADORES SOBRE GLOBALIZACIÓN Y TERRITORIO. Belo Horizonte, 1 al 4 de octubre.

SOUZA, B. J. (1993). Desenvolvimento Polarizado e Desequilíbrios Regionais no Brasil. Revista Análise Econômica UFRGS. Porto Alegre, n. 19, pp. 29-59.

SPOSITO, E. e MATUSHIMA, M. K. (2002). "A dinâmica econômica no Estado de São Paulo: do paradigma de área ao paradigma de eixo de desenvolvimento". In: SILVA, J. e SILVEIRA, M. (orgs.). Geografia econômica: temas regionais. Presidente Prudente, FCT/Unesp/PPGG.

VAINER, C. B. (2000). “Pátria, empresa e mercadoria: notas sobre a estratégia discursiva do Planejamento Estratégico Urbano". In: OTILIA, A.; VAINER, C. e MARICATO, E. A cidade do pensamento único: desmanchando consensos. Petrópolis/RJ, Vozes.

(2001). "Pátria, empresa e mercadoria: notas sobre a estratégia discursiva do Planejamento Estratégico Urbano". In: OTILIA, A; VAINER, C. e MARICATO, E. A cidade do pensamento único: desmanchando consensos. Petrópolis/RJ, Vozes.

VILLAÇA, F. (1998). Espaço intra-urbano no Brasil. São Paulo, Studio Nobel.

Texto recebido em 18/ago/2015

Texto aprovado em 19/fev/2016 
